\title{
A CASE OF LARGE BOWEL INJURY SECONDARY TO PEIVIC RING DISRUPTION
}

\author{
Brigadier A. P. DIGNAN, M.D., F.R.C.S., Late R.A.M.C. * \\ Captain J. A. R. SMITH, M.B., F.R.C.S., F.R.C.S.(Edin.), R.A.M.C. † \\ Military Hospital, Tidworth
}

SUMMARY: An infrequently reported large bowel injury, secondary to disruption of the pelvis is recorded. The mechanism of the injury is discussed. The importance of having a high index of suspicion of pelvic fractures, especially when ileus is prolonged, is stressed.

\section{Introduction}

Fractures of the pelvis are common. They are often associated with injury to soft tissue of the musculo-skeletal system, the nervous system and to the genito-urinary viscera. Not unusually, they are also accompanied by intestinal dysfunction resulting from retroperitoneal haematoma formation.

However, the occurrence of direct trauma to small and large bowel from the fragments is less well recorded. Furthermore, entrapment of the colon in the fracture has not often been reported.

A case of injury to the large bowel and its mesentery in association with severe fractures of the pelvis is reported and the literature reviewed.

\section{Case report}

A 33 year old male civilian, was admitted to hospital on 30 October 1971, his car having been involved in a side to side collision with an articulated lorry.

He complained of pain in both hips, right thigh, right side of abdomen and the anterior chest wall. He had not passed urine since his accident, about one hour prior to his admission.

On examination, the patient was very obese and was in a state of clinical shock, with cold clammy skin, pulse rate of $88 / \mathrm{min}$ and blood pressure $100 / 60 \mathrm{mmHg}$. There were multiple abrasions and bruises on his chest wall. His right thigh was swollen. There was deformity and swelling of his right ankle. He had a palpable fracture of his right patella. Passive movement of both legs and ankles was painful.

There was tenderness in the lower abdomen, most marked on the right side where muscle guarding was present. He had no palpable organomegaly and bowel sounds were normal. Apart from the right dorsalis pedis, the peripheral pulses in his lower limbs were palpable. He had no neurological deficit.

Radiography of the pelvis demonstrated:

a. Distraction of the symphysis pubis. b. Disruption of the left sacro-iliac joint. c. Fracture through the right acetabulum with depression of one large fragment causing central dislocation of the hip joint. d. Fracture of both pubic rami (Fig. 1).

\footnotetext{
* Now Major-General A. P. Dignan, Director of Army Surgery, Ministry of Defence.

+ Now Major J. A. R. Smith (Retd.), 63A Queen's Road, Aberdeen.
} 


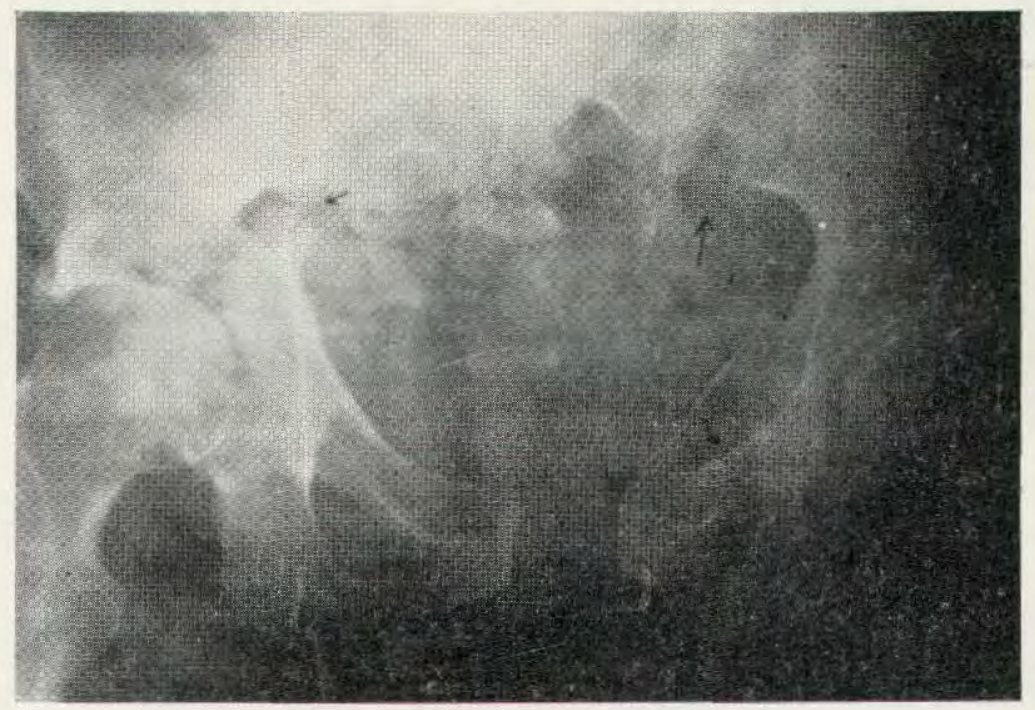

Fig. 1. Radiograph of the pelvis.

There was also radiological evidence of a right Pott's fracture and fractures of the 3 rd to the 8 th left ribs.

His immediate resuscitation was with 0.5 litre of Hartmann's solution followed by three packs of whole blood over a period of three hours. During this period his blood pressure rose to $130 / 90 \mathrm{mmHg}$ and his pulse rate did not increase. However, his abdomen became distended and bowel sounds scanty. The tenderness and muscle guarding persisted and it was decided to proceed to laparotomy.

Laparotomy was preceded by the passage of a catheter per urethram introduced with ease. Clear urine was withdrawn. The findings at laparotomy were as follows:

a. Haemoperitoneum. b. A $20 \mathrm{~cm}$ long tear in the mesentery of the terminal ileum with avascular changes in a $30 \mathrm{~cm}$ segment of the gut. c. A $15 \mathrm{~cm}$ laceration of the pelvic mesocolon with almost complete disruption of an area of the bowel wall about $5 \mathrm{~cm} x$ $2.5 \mathrm{~cm}$ adjacent to the damaged mesentery. d. Bladder wall bruised but intact. e. Extensive retroperitoneal haematoma.

The avascular terminal ileum was resected with end to end anastomosis. The traumatised loop of pelvic colon was exteriorised and excised after the manner of Paul Mickulicz, a glass Paul's tube being inserted into the proximal stoma and a crushing clamp placed across the distal stoma.

Attempts to reduce his right acetabulum fracture from within the pelvic cavity were unsuccessful and at the end of the operation, continuous skeletal traction to the right lower limb was instituted.

His postoperative progress was slow but uneventful apart from the development of transient E.C.G. changes compatible with direct trauma to the chest. The Pott's fracture was treated by manipulation of the fragments under general anaesthesia and plaster of Paris immobilisation when his ankle swelling had subsided sufficiently. It was not possible to correct the displacement of his left sacro-iliac joint or to achieve 
satisfactory reduction of the fracture of the right acetabulum. Mobilisation of the patient with gradual increase in the amount of weight bearing was commenced about six weeks after his ankle fracture had been manipulated. After a long period of convalescence and rehabilitation, the colostomy was closed extraperitoneally. About a week later he developed a faecal fistula which, however, in due course healed spontaneously. When he was discharged from hospital he was walking well with the aid of one stick and he had no alimentary upset. He subsequently returned to work.

\section{Discussion}

Direct injuries to genito-urinary organs, the rectum, the peripheral nervous system and the musculo-skeletal system and indirect interference with bowel function resulting from retroperitoneal haematoma, are all well recognised and widely reported complications of pelvic fractures. It is estimated that twenty per cent of pelvic fractures are complicated by visceral injuries, whilst some series, report an incidence of associated injuries as high as sixty per cent. However, trauma to intestine other than the rectum is rarely recorded.

Moore (1966) reported 26 cases of intestinal injury in 1309 patients with fractures of the pelvis. Peltier (1965) reported three cases of ruptured ileum and two of injury to the colon in a series of 186 patients.

Entrapment of bowel in the fracture as being the mechanism of injury to the gut has also been rarely mentioned. Lunt (1970) in his reference to the vast literature on pelvic fractures and their complications found only one report (Arnold 1907) of actual entrapment of bowel within a pelvic fracture.

In Moore's and Peltier's series, this type of injury to the gut was not mentioned. Lunt has recorded in his personal series three cases in which bowel was found to be entrapped in the fracture fragment. In addition, he reports one case in which the gut appeared to have been nipped by the opening and closing of the fragment at the time of injury. He emphasised that ileus is a relatively frequent sequel to trauma to the pelvis and that as a result, bowel entrapment may not be recognised until function returns to all but the mechanically obstructed segment of the gut. He makes the plea for early laparotomy when intraperitoneal complications are suspected-" Better to look and see, than wait and see."

In the case described here, it is likely that the tear in the small bowel mesentery was due to the sudden compression of the pelvic ring at the time of impact, or to localised displacement of the bowel associated with the central dislocation of the hip joint. However, the traumatised segment of the pelvic colon and its mesentery, on the other hand was in anatomical relationship to the site of disruption of the patient's left pelvic ring, the hinge type of fracture, described by Apley (1963). It is reasonable to postulate, that the latter part of the bowel and its mesentery were nipped as the fragments " unhinged " and were therefore momentarily entrapped.

It is to be observed that his abdominal symptoms and signs were predominantly right sided, presumably because of the ischaemia of the small gut, precipitated by the injury to its mesentery. In the absence of this latter injury, the trauma to the patient's large bowel would have been masked by the ileus caused by his retroperitoneal haematoma. Furthermore, it is possible that because of the frequent incidence of ileus in cases of fracture of the pelvis, minor degrees of injury to the bowel of this nature may be more common than is realised. 


\section{Conclusion}

It is well known that complications are rare in the presence of isolated pelvic fractures but are common when the pelvic ring is disrupted.

The disruption may result from an antero-posterior compression force in which the pubic rami on both sides are fractured. However, it may also be caused by hinge force applied to one blade of the ileum when the pelvis is " opened out" with disruption of the symphysis and of the sacro-iliac joint.

The presence of a large bowel injury should be suspected when the pelvic ring is disrupted in this way, and where the bowel function fails to return to normal in the usually accepted time interval for paralytic ileus.

\section{REFERENCES}

Apley, A. G. (1963). A System of Orthopaedics and Fractures. 2nd ed. Butterworths. London. P. 335. ARNOLD, G. J. (1907). A case of fracture of the pelvis with nipping of small intestine between the fragments. Lancet i, 1157 .

LUNT, H. R.'W. (1970). Entrapment of bowel with fractures of the pelvis. Injury 2, 121.

MoOre, J. R. (1966). Pelvic fractures: Associated with intestinal and mesenteric lesions. Canad. J. Surg. $9,253$.

PeLTIER, L. F. (1965). Complications associated with fractures of the pelvis. J. Bone Jt. Surg. 47a, 1060.

\section{A New Nuffield Centre in London}

THE new Nuffield Centre in London opened its doors at Villiers House, John Adam Street, W.C. 2 on June 4th, near Charing Cross Station, some year and a half after the old centre in Adelaide Street was forced to close down because of redevelopment of the area. The new, architecf-designed premises are on the ground floor of Villiers House and formerly were used as part of the out-patients department of Charing Cross Hospital.

They provide a comfortable lounge with a disco area, colour television, a modern bar, a small restaurant serving substantial snacks, and washing facilities. In addition, an information desk provides details of what's on in London, times of trains, accommodation in the area and is also the focal point for the issue of complimentary theatre and cinema tickets generously provided for the Forces by a number of managements in London.

The Centre is under the management of Flight Lieutenant Frank Stead, R.A.F. (Retd.), who ran the old centre at the time of closure. The new centre, of course, is open only for Service men and women.

The Nuffield Trust was set up in 1939 through the generosity and foresight of the late Lord Nuffield. Its aim is to promote the efficiency and welfare of the Forces by the provision of facilities for recreation and other means. At the end of 1973, a total of more than $£ 7$ million had been made available to the Services, while running costs of the Trust had been kept to 1.25 per cent. During its 24 years at Adelaide Street, the former Centre was used by at least 2,100,000 Service men and women. 